\title{
The vatitination of the employ of Licorice, Gingko e Arctium lappa to let piercing-lovers to wear these jewels even in intimate mucosae
}

\author{
Piotr Brzeziński ${ }^{1}$, Lorenzo Martini ${ }^{1,2}$
}

${ }^{1}$ University of Siena, Department of Pharmaceutical Biotechnologies, Via A. Moro 2, 53100 Siena, Italy, ${ }^{2}$ C.R.I.S.M.A. Inter University Centre for Researched Advanced Medical Systems

Corresponding author: Prof. Lorenzo Martini, E-mail: martini36@unisi.it

\section{INTRODUCTION}

Legend has it that in the XVII century copper miners at Siersleben in Saxony began to notice severe skin diseases and odd nervous manifestations and thought that the real cause was a "dark red ore" hidden in the same copper and supposed that a sort of goblins (gnomes) used to reside inside the ores themselves to protect the brightness and purity of the copper [1].

In the XVIII century a method was discovered to extract the black ore from the red metal: these veins were not but nickel and it was discovered too that many sources of this dark metal was laying underneath the masses of copper.

Nickel was easier to be extracted, was cheaper and more malleable in order to produce and create jewelry and bijouterie and more resistant to corrosion and rust.

At the end of 70s of last century 1110 US volunteers was prayed to wear bracelets made of nickel and the $9 \%$ of them showed a severe allergy breaking out.

The proof was repeated in 2008 and the number of volunteers who reacted to nickel was tripled [2]. Nowaday 250000 in US are the children under 12 y. who are allergic to nickel.

Nickel allergy is also more prevalent in women (17.1\%) than men $(3 \%)$, possibly due to cultural norms related to jewelry and ear piercings and therefore increased exposure to nickel [3].
Nickel is a cheap and widely available core metal.

Today, it can be found in a wide variety of items including jewelry, zippers, buttons, belt buckles, coins, cell phones, guitar strings, tablets, surgical implants, and certain foods.

Nickel is the most common cause of contact allergy. This is because nickel ions can easily be released from certain metals and react with the skin. Examples of objects that can cause nickel allergy are jewellery, watches, zippers, buttons, keys and coins. The allergy starts with the skin having been exposed to nickel through direct contact over a sustained period. Upon renewed contact with objects which give off nickel the problem can re-occur and the allergy is lifelong. It is normal for those who are allergic to nickel to have hand eczema. The risk of hand eczema increases if a person often is in contact with soap, water, solvents and other irritating substances which may cause skin dryness. Nickel allergy can, in certain cases, cause such severe problems that one is forced to change employment in order to reduce exposure to the substances and materials which trigger the allergy. There are metal alloys which contain nickel but which do not cause allergy problems since the nickel is strongly integrated and is not released. One example is stainless steel. On the other hand there are other alloys which contain nickel but where the substance is easily released; such an example is nickel silver.

The prevalence of metal allergy is high in the general population, and it is estimated that up to $17 \%$ of women

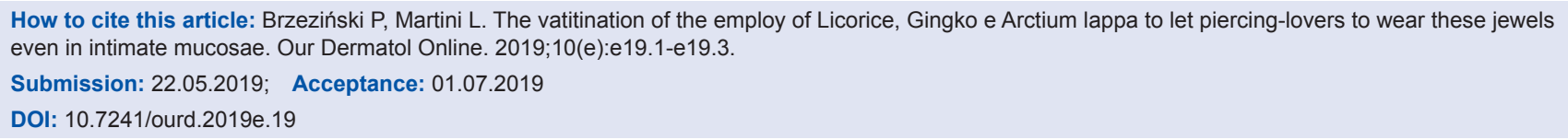


and $3 \%$ of men are allergic to nickel and that 1-3\% are allergic to cobalt and chromium. Among dermatitis patients, the prevalence of metal allergy is even higher. Metal allergy is mainly an environmental disorder and slight mutations in the filaggrin gene complex were recently suspected to be associated with nickel allergy and dermatitis. Environmental metal exposures include jewelry, buttons, clothing fasteners, dental restorations, mobile phones, and leather. Although consumer exposure is responsible for most cases of metal allergy, the importance of occupational metal exposure remains present and should always be taken into consideration when one interprets allergic patch test reactions to metals. Traditionally, nickel, cobalt, and chromium have been the most important contact allergens. However, recently, gold and palladium have drawn much attention as the prevalence of contact allergy to these metals is high. Palladium allergy is mainly a result of crosssensitization to nickel, whereas gold allergy is rarely clinically relevant when one takes its high prevalence into account. The epidemiology of metal allergy has recently changed in Europe as nickel allergy among ear-pierced Danish women has decreased following regulatory intervention on nickel release from consumer products. In the United States, the prevalence of nickel allergy is still increasing, which may be explained by the absence of regulation. The prevalence of chromium allergy is increasing in the United States, Singapore, and Denmark among dermatitis patients. This increase is significantly associated with leather exposure in Denmark. Metal allergy may result in allergic contact dermatitis and systemic allergic (contact) dermatitis. Furthermore, metal allergy has been associated with device failure following insertion of intracoronary stents, hip and knee prostheses, as well as other implants. This area is in need of more research.

The evident manifestations of the Ni-allergy are inflammation, erythema, itch and oedema and thus the AA had to look for some natural remedy that is capable to defeat this syndrome, but before to reveal the natural formula it is better to introduce the chief problem of the dismetabolism of the human Filaggrin gene [4].

It is ascertained that the loss-of-function mutations in FLG, the human gene encoding profilaggrin and filaggrin, have been identified as the cause of the common skin condition ichthyosis vulgaris (which is characterized by dry, scaly skin). These mutations, which are carried by up to $10 \%$ of people, also represent a strong genetic predisposing factor for atopic eczema, asthma and allergies. Profilaggrin is the major component of the keratohyalin granules within epidermal granular cells. During epidermal terminal differentiation, the $\sim 400 \mathrm{kDa}$ profilaggrin polyprotein is dephosphorylated and rapidly cleaved by serine proteases to form monomeric filaggrin $(37 \mathrm{kDa})$, which binds to and condenses the keratin cytoskeleton and thereby contributes to the cell compaction process that is required for squame biogenesis. Within the squames, filaggrin is citrullinated, which promotes its unfolding and further degradation into hygroscopic amino acids, which constitute one element of natural moisturising factor. Loss of profilaggrin or filaggrin leads to a poorly formed stratum corneum (ichthyosis), which is also prone to water loss (xerosis).

Recent human genetic studies strongly suggest that perturbation of skin barrier function as a result of reduction or complete loss of filaggrin expression leads to enhanced percutaneous transfer of allergens. Filaggrin is therefore in the frontline of defence, and protects the body from the entry of foreign environmental substances that can otherwise trigger aberrant immune responses [5].

Manifold are the substances researchers have been attempting from decades to use in order to promote filaggrin in skin diseases where filaggrin production is lacking or deficient, for instance $\mathrm{N}$-quinolylbenzamide derivative, ivermectin or a phenylalanine amide derivatives.

Such basic treatment of atopic dermatitis, the removal of the onset and deterioration factors, have been made by combining a drug therapy to suppress the correction and inflammation of abnormal skin features. Further, as the main skin dysfunction in atopic dermatitis, decrease water retention capacity barrier function of the stratum corneum, reduction of itching threshold include compromised.

Previously, as a component for promoting the production of FLG, Keburanin compound (Patent Document 1: JP 2009-256269 JP), liquiritin (Patent Document 2: JP 2003-146886 JP), glycolipids (JP 3: JP 2006-241095 JP), rosmarinic acid and eriodictyol -7-O-rutinoside (Patent Document 4: JP 2010-90037 JP).

Liquiritin is extracted from Glycerrhiza glabra dried root in boiling water.

In effect boiling the Licorice root in water it is possible to extract many flavonoids and diverse 
isoflavones, e.g.: amongst the flavonoids it is possible to extract liquiritin, liquiritigenin, hamnoliquiritin, neoliquiritin, chalcones isoliquiritin, isoliquiritigenin, neoisoliquiritin, licuraside, glabrolide, licoflavonol, 5,8-dihydroxy-flavone-7-O-beta-D-glucuronide, glychionide $\mathrm{A}$, and 5-hydroxy-8-methoxyl- flavone7-O-beta-D-glucuronide and glychionide B and amongst the Isoflavones it is possibile to have available: glabridin, galbrene, glabrone, shinpterocarpin, licoisoflavones A and B, formononetin, glyzarin, kumatakenin, hispaglabridin A, hispaglabridin B, 4'-O-methylglabridin and 3'-hydroxy-4'-Omethylglabridin, glabroisoflavanone $\mathrm{A}$ and $\mathrm{B}$ glabroisoflavanone B $[6,7]$.

For this reason the AA have chosen to ideate a treatment based on the usage of these three elements: Decoction of Licorice root (to promote the filaggrin production) Hydroglyceric extract of Gingko Biloba, Japanese silver apricot, (to reduce the itch, erythema and oedema) Arctium lappa water (that is an optimal depurative when used topically).

It must be stressed that Gingko biloba leaves may release the glycosides only in presence of water and glycerin, and therefore gingkolide $\mathrm{C}, \mathrm{B}$ and bilobalide can be extracted in a solution of 50:50 of water and glycerin.

The AA have already heralded the therapeutic treatment before and they have recruited a young girl (22 y. old) who wears a piercing on her nipple and right after one week she began to wear the piercing, her teat presented all the manifestations of a Ni-allergy: redness, itch, inflammation and oedema.

She had fever in the night and pain was conspicuous all the day, even if she did not renounce to eliminate her jewel from the nipple.
She was prayed to apply the lotion three times a day for one entire week.

The AA observed a complete remission of the state of inflammation and allergy after the $6^{\text {th }}$ day.

The AA are just deciding to proof in the next future the lotion as a preventive remedy, to suggest to whoever desires to wear a piercing in intimate zones of the epidermis or mucosae.

\section{Consent}

The examination of the patient was conducted according to the Declaration of Helsinki principles.

\section{REFERENCES}

1. Baldwin WH: The story of nickel. How "old nick's" gnomes were outwitted; Journal of Chemical Education; 1931:8:1749.

2. Rietschel RL, Fowler JF, Warshaw EM, Belsito D, DeLeo VA, Maibach HI, et al. Detection of nickel sensitivity has increased in North American patch-test patients. Dermatitis. 2009;19:16-9.

3. Thyssen JP, Menné T. Metal allergy--a review on exposures, penetration, genetics, prevalence, and clinical implications. Chem Res Toxicol. 2010;23:309-18.

4. Thyssen JP, Menné T. Metal allergy--a review on exposures, penetration, genetics, prevalence, and clinical implications. Chem Res Toxicol. 2010;23:309-18.

5. Sandilands A, Sutherland C, Irvine AD, WHI Lewin. Filaggrin in the frontline: role in skin barrier function and disease. J Cell Sci. 2009;122:1285-94.

6. Li JR, Wang YQ, Deng ZZ. Two new compounds from Glycyrrhiza glabra. J Asian Nat Prod Res. 2005;7:677-80.

7. Kinoshita T, Tamura $\mathrm{Y}$ and Mizutani $\mathrm{K}$. The isolation and structure elucidation of minor isoflavonoids from licorice of Glycyrrhiza glabra origin. Chem Pharm Bull. 2005;53:847- 49.

Copyright by Piotr Brzeziński, et al. This is an open-access article distributed under the terms of the Creative Commons Attribution License, which permits unrestricted use, distribution, and reproduction in any medium, provided the original author and source are credited. Source of Support: Nil, Conflict of Interest: None declared. 